\title{
Anti-citrullinated protein antibodies are associated with osteopenia but not with pain at diagnosis of rheumatoid arthritis: data from the BARFOT cohort
}

Ingiäld Hafström ${ }^{1 *}$, Sofia Ajeganova ${ }^{2,3}$, Kristina Forslind $^{4,5}$ and Björn Svensson ${ }^{6}$

\begin{abstract}
Background: Anti-citrullinated protein antibodies (ACPA) have been suggested to have a potential role in both bone loss and pain in rheumatoid arthritis (RA), based on studies in vitro and in animal models. Here we addressed if anti-cyclic citrullinated (anti-CCP) antibodies were associated with osteopenia or pain in patients with RA, at the time for diagnosis.

Methods: Baseline data from the BARFOT (Better Anti-Rheumatic PharmacOTherapy) cohort, which consists of patients with RA with a disease duration of 1 year or less, were analyzed. To be included, they should have been assessed by anti-CCP, dual-energy X-ray absorptiometry (DEXA) of lumbar spine and hip, and/or digital X-ray radiogrammetry (DXR) of the metacarpal bones. Osteopenia was defined as a $z$-score $\leq-1$ SD. Pain VAS $>40 \mathrm{~mm}$, was defined as patient unacceptable pain. Multiple logistic regression analyses were performed to assess whether anti-CCP was independently associated with osteopenia or unacceptable pain.

Results: Of the 657 patients, 65\% were women, 58\% were anti-CCP positive, 37\% had osteopenia in the lumbar spine, and 29\% had osteopenia in the hip. Sixty-one percent had unacceptable pain at diagnosis. Patients positive for anti-CCP had significantly more frequently osteopenia in the femoral neck and Ward's triangle compared with anti-CCP-negative patients ( $p=0.016$ and 0.003 , respectively). This difference was found in men at any anti-CCP titer, but in women, osteopenia in these hip locations was found only in those with high anti-CCP titers (> 500 IU/ $\mathrm{ml}$ ). Anti-CCP was not associated with osteopenia in the lumbar spine or the metacarpal bones. In multiple logistic regression analyses, anti-CCP was independently associated with osteopenia in the femoral neck and/or Ward's triangle but not with unacceptable pain. Instead, inflammatory variables were independently associated with unacceptable pain.

Conclusion: These data show that in patients with early RA, anti-CCP positivity was independently associated with osteopenia in the femoral neck and/or Ward, but not in the lumbar spine. In our patients, we could not confirm a recently suggested association between anti-CCP antibodies and pain. Further studies are necessary to explore the possible clinical relevance of interactions between ACPA, bone, and pain found in vitro and in animal models.
\end{abstract}

Keywords: Rheumatoid arthritis, Anti-citrullinated protein antibodies, Bone mineral density, Pain

\footnotetext{
* Correspondence: ingiald.hafstrom@karolinska.se

${ }^{1}$ Division of Gastroenterology and Rheumatology, Department of Medicine,

Huddinge, Karolinska Institutet, and Rheumatology unit R92, Karolinska

University Hospital, Stockholm, SE 141 86, Sweden

Full list of author information is available at the end of the article
}

(c) The Author(s). 2019 Open Access This article is distributed under the terms of the Creative Commons Attribution 4.0 International License (http://creativecommons.org/licenses/by/4.0/), which permits unrestricted use, distribution, and reproduction in any medium, provided you give appropriate credit to the original author(s) and the source, provide a link to the Creative Commons license, and indicate if changes were made. The Creative Commons Public Domain Dedication waiver (http://creativecommons.org/publicdomain/zero/1.0/) applies to the data made available in this article, unless otherwise stated. 


\section{Introduction}

Many patients with rheumatoid arthritis (RA) have osteopenia and pain as prominent features, often not associated with clinical joint inflammation [1-4]. Possible mechanisms responsible for inflammation-independent osteopenia or pain have been proposed, among these a potential role for anti-citrullinated protein antibodies (ACPA) [5].

Presence of ACPA analyzed by the anti-cyclic citrullinated antibodies test (anti-CCP2) has been found in $0.8 \%$ of the general non-RA population. In these individuals, joint pain was significantly more frequent than in the anti-CCP-negative group [6]. Furthermore, anti-CCP-positive individuals with unspecific musculoskeletal complaints, including joint pain, had a high risk of developing RA [7]. It should though be noted that anti-CCP-negative RA exists, a disease with a heterogenous course, in which the prognosis also could be severe.

ACPAs detectable as anti-CCP antibodies, as well as other autoantibodies, may appear in blood prior to the clinical onset of RA $[8,9]$. The ACPA immune response starts in a restricted manner and the number of recognized citrullinated peptides increases in the period preceding disease onset [10-12]. With time, also the ACPA levels increase, markedly 2-4 years prior to a diagnosis of RA, alongside a rise in inflammatory cytokine levels $[13,14]$.

Monoclonal ACPA derived from patients with RA can in vitro cause differentiation of human osteoclasts and induce trabecular bone loss in mice $[15,16]$. Osteoclasts stimulated by ACPA secrete, as the main mediator, the cytokine interleukin (IL)-8. This cytokine is not only an autocrine growth factor for osteoclasts but can also induce pain in mice in the absence of inflammation, probably by sensitizing or activation of the sensory neurons $[16,17]$. These studies provided a possible role of ACPA in both bone loss and pain.

In healthy anti-CCP-positive individuals, cortical bone loss in the metacarpophalangeal joints (MCP) has been reported [18]. Furthermore, in ACPA-positive subjects with arthralgia, trabecular thinning of MCP has been observed [19]. However, in the early treatment-naive RA, bone mineral density (BMD) is preserved in most patients [20]. A recent study has shown that anti-CCP positivity is associated with reduced BMD, especially of the trabecular bone in the lumbar spine [21]. Interestingly, anti-CCP at any level in that study negatively affected the spine BMD while BMD in the hip was affected by high anti-CCP titers only [21].

The potential association of ACPA and pain intensity has however not been studied.

The aim of the present study was to assess whether ACPA measured as anti-CCP was associated with BMD or pain in the initial stage of RA and thereby to have a possible role in bone loss and pain perception. For this study, we took advantage of the cohort of early RA patients recruited to the Better Anti-Rheumatic PharmacOTherapy (BARFOT) cohort in 1993-1999, provided that the patients had measurements of BMD in the hip and lumbar spine and/or metacarpophalangeal bone.

\section{Patients and methods}

\section{Study design and population}

The BARFOT cohort is recruited from six centers, which cover both urban and rural referral areas. It is an observational study designed to investigate the course and long-term prognosis of RA. The inclusion criteria were a diagnosis of RA according to the ACR classification criteria [22] and a disease duration of 12 months or less [23]. In all 909 patients, 18 to 80 years of age, not previously treated with disease-modifying anti-rheumatic drugs (DMARDs) or glucocorticoids, were recruited from October 1993 to November 1999.

For this study, patients were eligible if they had measured anti-CCP, bone mineral density (BMD) with dual-energy X-ray absorptiometry (DEXA) $(n=557)$ and/or digital X-ray radiogrammetry (DXR) of the metacarpal bones on hand radiographs $(n=391)$ at baseline. A total of 657 patients satisfied these criteria. The patients with missing data, 252 patients, had similar baseline characteristics as those included into this study (data not shown).

\section{Disease activity and physical function}

Disease activity was assessed by C-reactive protein (CRP) and the Disease Activity Score calculated on 28 joints (DAS28, range 0-9.4) [24]. For patients assessed early in the BARFOT study, their original DAS values at inclusion were transformed to DAS28 using the formula described by van Gestel et al. [25].

Pain was measured on a visual analogue scale (VAS) (0-100 mm, least to worst). Patient unacceptable pain state was defined as pain VAS $>40 \mathrm{~mm}$ [26].

The Swedish version of the Stanford Health Assessment Questionnaire (HAQ) was used to measure daily life function [27].

\section{Laboratory analyses}

Plasma and serum samples were stored at $-70{ }^{\circ} \mathrm{C}$ until assay. Antibodies to cyclic citrullinated peptides (anti-CCP) were detected using the ELISA CCP2 test (Euro-Diagnostica, Malmö, Sweden) at three medical centers, and positive anti-CCP was defined as > $25 \mathrm{IU} /$ $\mathrm{ml}$. Rheumatoid factor was analyzed by agglutination test at different centers, while only serostatus was used. A titer of $20 \mathrm{IU} / \mathrm{ml}$ was regarded as positive. 


\section{Bone mineral density}

BMD at the lumbar spine (L1 and L2-L4) and at the left hip (femoral neck, Ward's triangle, and greater trochanter) was measured by dual-energy X-ray absorptiometry (DEXA) with a Lunar densitometer. DEXA-BMD was expressed as the number of standard deviations (SD) from the mean of healthy age- and sex-matched people, the z-score. The values were obtained from Lunars combined European/US reference population (Expert-XL software version 1.7, Lunar Corp. Madison, USA, 1998). The $\mathrm{z}$-scores were used to minimize the effect of age and gender. The lowest $\mathrm{z}$-score in the lumbar spine is given, and for the hip area, separate $\mathrm{z}$-scores for femoral neck, Ward's triangle, and trochanter were given. Reduced bone mass was defined as a $\mathrm{z}$-score $\leq 1.0 \mathrm{SD}$ below the mean value measured by the DEXA.

Digital X-ray radiogrammetry (DXR) was used to measure cortical BMD of the three middle metacarpal bones on hand radiographs at baseline. Analogue X-ray films of hands were digitized using a Vidar Diagnostic Pro plus, 300 dpi, 12 bit (VIDAR Systems Corp., Herndon, VA, USA). DXR-BMD was measured on the digitized images by DXR-online (Sectra, Linköping, Sweden). The technique has been described in detail previously $[28,29]$. In short, this method provides a BMD estimate in grams per square centimeter based on an automated analysis of the geometry and texture of the cortical bone of the three middle metacarpals. The estimated DXR-BMD was compared to a reference database of healthy age- and sex-matched individuals to calculate z-scores. Osteopenia was defined as z-score $\leq 1.0$ SD below the mean value measured by DXR [30].

\section{Statistics}

Statistical analyses were performed using IBM SPSS statistical software v21.0. To test differences between groups, the $T$ test was used for independent groups and the chi-square test for proportions. Correlations were performed by Spearman's test.

Multiple logistic regression analyses were performed to assess whether anti-CCP independently predicted osteopenia or unacceptable pain. The models initially included possible confounders and other potential independent predictors, i.e., age, gender, disease duration, smoking habits, body mass index (BMI), DAS28, CRP, and HAQ, but not the rheumatoid factor (RF) due to high correlation with anti-CCP $(r=0.7)$. Variables failing to meet a threshold of $p<0.25$ were removed.

\section{Results}

Patient characteristics and anti-CCP status

A total of 657 patients with early RA, for whom baseline anti-CCP and BMD measurements were available, were included. Mean (SD) age was 57 (15) years, 58\% were
anti-CCP positive and $60 \%$ RF positive. Of the study population, $65 \%$ were women, of whom $58 \%$ were postmenopausal. All patients had active disease, DAS28 mean (SD) 5.2(1.2), and mean (SD) pain VAS 47 (24) $\mathrm{mm}$, and $61 \%$ had pain VAS $>40 \mathrm{~mm}$. None of the patients were treated with bisphosphonates or vitamin D supplements.

Table 1 shows the characteristics of the patients according to anti-CCP status. Anti-CCP-positive patients were more often ever smokers, were positive for RF, and had higher ESR, CRP, and pain (only men) but less tender joints (only women) than anti-CCP-negative patients.

The same differences in clinical characteristics were present when comparing patients with anti-CCP titer above $500 \mathrm{IU} / \mathrm{ml}$ with anti-CCP-negative patients, except for pain and tender joints which were similar (data not shown).

\section{Anti-CCP and bone mineral density}

A total of 557 patients had DEXA performed. Reduced bone mass, defined as osteopenia by DEXA, was found in $37 \%$ of the patents in the lumbar spine $35 \%$ in women and $41 \%$ in men) and in $29 \%$ in the femoral neck, Ward, or trochanter (28\% in women and $30 \%$ in men).

Patients positive for anti-CCP had significantly more often osteopenia in the femoral neck and Ward than anti-CCP-negative patients, but when separating the patients per gender, this difference was found only in men (Table 2).

We therefore compared the women who were 50 years or older with those below 50 (median menopausal age was 49.1 years). In these two age subgroups, z-scores in the hip compartments did not differ between anti-CCP-positive and anti-CCP-negative patients (data not shown), except for anti-CCP-positive women 50 years or older who had more often osteopenia in Ward than those negative, $24 \%$ and $7 \%$ respectively $(p=0.009)$.

Lumbar BMD was not affected by anti-CCP status, neither in women nor in men (Table 2), not even when controlling for disease activity measured by DAS28 (data not shown).

To explore further the influence of anti-CCP on osteopenia, we performed analyses of the effects of high anti-CCP titers on bone mass. For these analyses, we applied a titer above $500 \mathrm{IU} / \mathrm{ml}$ (median titer was $475 \mathrm{IU} / \mathrm{ml}$ ).

A total of 180 patients had an anti-CCP titer above $500 \mathrm{IU} / \mathrm{ml}, 103$ women and 77 men. Both women and men with such a high titer had significantly higher frequency of osteopenia in the femoral neck and/or Ward than those who were anti-CCP negative (Table 3). Of interest, this high anti-CCP titer was not associated with osteopenia in the lumbar spine in any gender. 
Table 1 Patients and baseline disease characteristics split by anti-CCP status and gender

\begin{tabular}{|c|c|c|c|c|c|c|c|c|c|}
\hline & \multicolumn{3}{|c|}{ All patients } & \multicolumn{3}{|l|}{ Women } & \multicolumn{3}{|l|}{ Men } \\
\hline & \multicolumn{2}{|c|}{ Anti-CCP } & \multirow[t]{3}{*}{$p$ value } & \multicolumn{2}{|l|}{ Anti-CCP } & \multirow[t]{3}{*}{$p$ value } & \multicolumn{2}{|l|}{ Anti-CCP } & \multirow[t]{3}{*}{$p$ value } \\
\hline & Positive & Negative & & Positive & Negative & & Positive & Negative & \\
\hline & $n=378$ & $n=279$ & & $n=244$ & $n=184$ & & $n=134$ & $n=95$ & \\
\hline Age, years & 56 & 58 & 0.23 & 55 & 54 & 0.33 & 58 & 65 & 0.01 \\
\hline Disease duration, months & 6 & 6 & 0.06 & 6 & 6 & 0.13 & 6 & 6 & 0.23 \\
\hline Ever smokers, \% & 66 & 55 & 0.006 & 61 & 51 & 0.046 & 74 & 63 & 0.07 \\
\hline $\mathrm{BMI}, \mathrm{kg} / \mathrm{m}^{2}$ & 25.4 & 25.5 & 0.60 & 24.9 & 25.5 & 0.23 & 26.0 & 25.5 & 0.36 \\
\hline RF-positivity, \% & 88 & 21 & 0.001 & 85 & 16 & 0.001 & 86 & 14 & 0.001 \\
\hline DAS28 & 5.3 & 5.2 & 0.19 & 5,3 & 5,3 & 0.66 & 5.2 & 4.9 & 0.10 \\
\hline Swollen joints, $n$ & 10 & 11 & 0.053 & 10 & 11 & 0.08 & 11 & 11 & 0.39 \\
\hline Tender joints, $n$ & 7 & 9 & 0.007 & 8 & 10 & 0.004 & 7 & 7 & 0.66 \\
\hline Patient global assessment VAS (0-100), mm & 46 & 45 & 0.71 & 49 & 48 & 0.69 & 41 & 40 & 0.83 \\
\hline $\mathrm{ESR}, \mathrm{mm}$ & 41 & 31 & 0.001 & 41 & 30 & 0.001 & 41 & 32 & 0.001 \\
\hline CRP, mg/l & 24 & 16 & 0.001 & 20 & 14 & 0.001 & 29 & 24 & 0.040 \\
\hline Pain VAS $(0-100), \mathrm{mm}$ & 49 & 45 & 0.020 & 51 & 47 & 0.15 & 47 & 40 & 0.042 \\
\hline Pain VAS > 40 mm \% & 65 & 56 & 0.021 & 66 & 59 & 0.13 & 62 & 50 & 0.07 \\
\hline HAQ (0-3) & 1.0 & 1.0 & 0.17 & 1.2 & 1.0 & 0.10 & 0.9 & 0.8 & 0.82 \\
\hline
\end{tabular}

$p$ values denote differences between groups. The values are mean (normally distributed) unless otherwise stated. Italicized $p$ values are significant. Anti-CCP positivity titer $>25 \mathrm{IU} / \mathrm{ml}$

$B M I$ body mass index, RF rheumatoid factor, DAS28 28 joints-Disease Activity Score, ESR erythrocyte sedimentation rate, CRP C-reactive protein, VAS visual analogue scale, HAQ Health Assessment Questionnaire

Table 2 Baseline bone mineral density, measured by DEXA and DXR, by anti-CCP status and gender

\begin{tabular}{|c|c|c|c|c|c|c|c|c|c|}
\hline & \multicolumn{3}{|l|}{ All patients } & \multicolumn{3}{|l|}{ Women } & \multicolumn{3}{|l|}{ Men } \\
\hline & \multicolumn{2}{|l|}{ Anti-CCP } & \multirow[t]{2}{*}{$p$ value } & \multicolumn{2}{|l|}{ Anti-CCP } & \multirow[t]{2}{*}{$p$ value } & \multicolumn{2}{|l|}{ Anti-CCP } & \multirow[t]{2}{*}{$p$ value } \\
\hline & Positive & Negative & & Positive & Negative & & Positive & Negative & \\
\hline \multicolumn{10}{|l|}{ DEXA } \\
\hline \multicolumn{10}{|l|}{ Lumbar spine } \\
\hline z-score, mean (SD) & $\begin{array}{l}-0.63 \\
(1.25)\end{array}$ & $\begin{array}{l}-0.46 \\
(1.39)\end{array}$ & 0.14 & $\begin{array}{l}-0.60 \\
(1.17)\end{array}$ & $\begin{array}{l}-0.53 \\
(1.25)\end{array}$ & 0.65 & $\begin{array}{l}-0.70 \\
(1.38)\end{array}$ & $\begin{array}{l}-0.31 \\
(1.62)\end{array}$ & 0.09 \\
\hline Osteopenia, \% & 38 & 36 & 0.54 & 35 & 35 & 0.99 & 44 & 36 & 0.34 \\
\hline \multicolumn{10}{|l|}{ Femoral neck } \\
\hline z-score, mean (SD) & $\begin{array}{l}0.05 \\
(1.24)\end{array}$ & $\begin{array}{l}0.03 \\
(0.96)\end{array}$ & 0.85 & $\begin{array}{l}0.17 \\
(1.29)\end{array}$ & $\begin{array}{l}-0.11 \\
(0.88)\end{array}$ & 0.07 & $\begin{array}{l}-0.14 \\
(1.13)\end{array}$ & $\begin{array}{l}0.31 \\
(1.06)\end{array}$ & 0.025 \\
\hline Osteopenia, \% & 18 & 9 & 0.016 & 14 & 9 & 0.30 & 25 & 8 & 0.017 \\
\hline \multicolumn{10}{|l|}{ Femoral Ward } \\
\hline z-score, mean (SD) & $\begin{array}{l}-0.07 \\
(1.14)\end{array}$ & $\begin{array}{l}0.20 \\
(1.16)\end{array}$ & 0.028 & $\begin{array}{l}0.00 \\
(1.14)\end{array}$ & $\begin{array}{l}0.11 \\
(1.10)\end{array}$ & 0.46 & $\begin{array}{l}-0.19 \\
(1.14)\end{array}$ & $\begin{array}{l}0.38 \\
(1.25)\end{array}$ & 0.009 \\
\hline Osteopenia, \% & 21 & 9 & 0.003 & 19 & 10 & 0.70 & 23 & 6 & 0.011 \\
\hline \multicolumn{10}{|l|}{ Femoral trochanter } \\
\hline z-score, mean (SD) & $\begin{array}{l}0.12 \\
(1.18)\end{array}$ & $\begin{array}{l}0.18 \\
(1.04)\end{array}$ & 0.64 & $\begin{array}{l}0.25 \\
(1.18)\end{array}$ & $\begin{array}{l}0.05 \\
(0.97)\end{array}$ & 0.19 & $\begin{array}{l}-0.10 \\
(1.17)\end{array}$ & $\begin{array}{l}0.43 \\
(1.14)\end{array}$ & 0.016 \\
\hline Osteopenia, \% & 18 & 14 & 0.29 & 15 & 17 & 0.66 & 23 & 6 & 0.018 \\
\hline \multicolumn{10}{|l|}{ DXR, metacarpal } \\
\hline z-score, mean (SD) & $-0.10(1.09)$ & $\begin{array}{l}-0.03 \\
(1.13)\end{array}$ & 0.52 & $\begin{array}{l}-0.24 \\
(1.15)\end{array}$ & $\begin{array}{l}-0.23 \\
(1.12)\end{array}$ & 0.74 & $\begin{array}{l}0.11 \\
(0.96)\end{array}$ & $\begin{array}{l}0.44 \\
(1.09)\end{array}$ & 0.047 \\
\hline Osteopenia, \% & 22 & 20 & 0.65 & 26 & 26 & 1.00 & 15 & 8 & 0.30 \\
\hline
\end{tabular}

$p$ values denote differences between groups, and italicized values are significant. Anti-CCP positivity titer $>25 \mathrm{IU} / \mathrm{ml}$ 
Table 3 Baseline bone mineral density measured by DEXA and DXR, by groups with anti-CCP > 500 IU/ml and anti-CCP negative

\begin{tabular}{|c|c|c|c|c|c|c|c|c|c|}
\hline & \multicolumn{3}{|l|}{ All patients } & \multicolumn{3}{|l|}{ Women } & \multicolumn{3}{|l|}{ Men } \\
\hline & \multicolumn{2}{|l|}{$\overline{\text { Anti-CCP }}$} & \multirow{3}{*}{$\begin{array}{l}p \\
\text { value }\end{array}$} & \multicolumn{2}{|l|}{$\overline{\text { Anti-CCP }}$} & \multirow{3}{*}{$\begin{array}{l}p \\
\text { value }\end{array}$} & \multicolumn{2}{|l|}{$\overline{\text { Anti-CCP }}$} & \multirow{3}{*}{$\begin{array}{l}p \\
\text { value }\end{array}$} \\
\hline & $>500 \mathrm{IU} / \mathrm{ml}$ & Negative & & $>500 \mathrm{IU} / \mathrm{ml}$ & Negative & & $>500 \mathrm{IU} / \mathrm{ml}$ & Negative & \\
\hline & $n=180$ & $n=277$ & & $n=103$ & $n=183$ & & $n=77$ & $n=94$ & \\
\hline \multicolumn{10}{|l|}{ DEXA } \\
\hline \multicolumn{10}{|l|}{ Lumbar spine } \\
\hline z-score, mean (SD) & $\begin{array}{l}-0.57 \\
(1.22)\end{array}$ & $\begin{array}{l}-0.48 \\
(1.36)\end{array}$ & 0.53 & $\begin{array}{l}-0.53 \\
(1.19)\end{array}$ & $\begin{array}{l}-0.53 \\
(1.25)\end{array}$ & 0.97 & $\begin{array}{l}-0.63 \\
(1.27)\end{array}$ & $\begin{array}{l}-0.37 \\
(1.55)\end{array}$ & 0.32 \\
\hline Osteopenia, \% & 33 & 36 & 0.56 & 31 & 36 & 0.52 & 35 & 37 & 0.85 \\
\hline \multicolumn{10}{|l|}{ Femoral neck } \\
\hline z-score, mean (SD) & $\begin{array}{l}-0.10 \\
(1.10)\end{array}$ & $\begin{array}{l}0.02 \\
(0.96)\end{array}$ & 0.32 & $\begin{array}{l}-0.04 \\
(1.18)\end{array}$ & $\begin{array}{l}-0.10 \\
(0.89)\end{array}$ & 0.69 & $\begin{array}{l}-0.19 \\
(0.99)\end{array}$ & $\begin{array}{l}0.28 \\
(1.05)\end{array}$ & 0.027 \\
\hline Osteopenia, \% & 23 & 9 & 0.002 & 22 & 9 & 0.028 & 24 & 8 & 0.036 \\
\hline \multicolumn{10}{|l|}{ Femoral Ward } \\
\hline z-score, mean (SD) & $\begin{array}{l}-0.19 \\
(1.12)\end{array}$ & $\begin{array}{l}0.18 \\
(1.16)\end{array}$ & 0.01 & $\begin{array}{l}-0.19 \\
(1.23)\end{array}$ & $\begin{array}{l}0.10 \\
(1.10)\end{array}$ & 0.13 & $\begin{array}{l}-0.20 \\
(0.96)\end{array}$ & $\begin{array}{l}0.35 \\
(1.25)\end{array}$ & 0.020 \\
\hline Osteopenia, \% & 22 & 9 & 0.004 & 23 & 10 & 0.035 & 20 & 6 & 0.043 \\
\hline \multicolumn{10}{|l|}{ Femoral trochanter } \\
\hline z-score, mean (SD) & $\begin{array}{l}-0.06 \\
(1.16)\end{array}$ & $\begin{array}{l}0.16 \\
(1.02)\end{array}$ & 0.13 & $\begin{array}{l}-0.03 \\
(1.30)\end{array}$ & $\begin{array}{l}0.05 \\
(0.98)\end{array}$ & 0.68 & $\begin{array}{l}-0.10 \\
(0.93)\end{array}$ & $\begin{array}{l}0.37 \\
(1.08)\end{array}$ & 0.032 \\
\hline Osteopenia, \% & 20 & 14 & 0.18 & 23 & 17 & 0.40 & 17 & 7 & 0.13 \\
\hline \multicolumn{10}{|l|}{ DXR, metacarpal } \\
\hline z-score, mean (SD) & $\begin{array}{l}0.01 \\
(1.08)\end{array}$ & $\begin{array}{l}-0.03 \\
(1.13)\end{array}$ & 0.80 & $\begin{array}{l}-1.13 \\
(1.23)\end{array}$ & $\begin{array}{l}-0.29 \\
(1.12)\end{array}$ & 0.40 & $\begin{array}{l}0.13 \\
(0.91)\end{array}$ & $\begin{array}{l}0.45 \\
(1.01)\end{array}$ & 0.09 \\
\hline Osteopenia, \% & 17 & 20 & 0.34 & 23 & 26 & 0.40 & 12 & 8 & 0.40 \\
\hline
\end{tabular}

$p$ values denote differences between groups, and italicized values are significant $D E X A$ dual-energy $\mathrm{X}$-ray absorptiometry, DXR digital X-ray radiogrammetry

We further analyzed if anti-CCP status was associated with cortical bone mass measured by DXR in the metacarpophalangeal bones. The frequency of osteopenia was not influenced by positive anti-CCP or by anti-CCP titers above $500 \mathrm{IU} / \mathrm{ml}$, neither in women nor in men (Tables 2 and 3 ).

\section{Predictors of osteopenia or pain}

Multiple logistic regression analyses with osteopenia in the femoral neck and/or Ward as the dependent variable showed that anti-CCP positivity was independently associated with osteopenia (Table 4).

If high levels of anti-CCP (above $500 \mathrm{IU} / \mathrm{ml}$ ) were included in the model instead of the categorical anti-CCP variable, the results became similar (data not shown).

When RF serostatus (yes/no) was included in the model instead of anti-CCP serostatus, no association with osteopenia in femoral neck/ward was found (data not shown). If both categorical anti-CCP and RF were included together, they were associated with osteopenia but with a lower odds ratio than anti-CCP alone (1.79 versus 2.05).
Multiple regression analyses to explain unacceptable pain showed that inflammation (DAS28) and HAQ, but not anti-CCP positivity, were independently associated with unacceptable pain (Table 5). Similar results were obtained if high-level anti-CCP (above $500 \mathrm{IU} / \mathrm{ml}$ ) was included in the model instead of the categorical anti-CCP variable (data not shown).

\section{Discussion}

In the present study of patients with early RA, osteopenia in lumbar spine and/or hip was found in about one third of the patients. Patients positive for anti-CCP had a higher frequency of reduced bone mass, osteopenia, in

Table 4 Multiple logistic regression with osteopenia of the femoral neck and/or Ward as the dependent variable

\begin{tabular}{lllllcl}
\hline & B & S.E. & Sig. & Exp(B) & \multicolumn{2}{c}{$95 \%$ Cl for EXP(B) } \\
\cline { 5 - 7 } & & & & & Lower & Upper \\
\hline Anti-CCP positivity & 0.719 & 0.277 & 0.009 & 2.053 & 1.193 & 3.535 \\
Female gender & -0.182 & 0.262 & 0.487 & 0.834 & 0.499 & 1.393 \\
Constant & -1.611 & 0.285 & 0.000 & 0.200 & & \\
\hline
\end{tabular}

Anti-CCP positivity $=>25 \mathrm{IU} / \mathrm{ml}$. Italicized value is significant 
Table 5 Multiple logistic regression with unacceptable pain as the dependent variable

\begin{tabular}{lllllll}
\hline & B & SE & Sig. & Exp(B) & \multicolumn{2}{c}{ 95\% Cl for EXP(B) } \\
\hline Age & & & & Lower & Upper \\
Disease duration, months & -0.009 & 0.006 & 0.159 & 0.991 & 0.979 & 1.003 \\
Anti-CCP positivity & -0.042 & 0.030 & 0.159 & 0.959 & 0.905 & 1.017 \\
DAS28 & 0.293 & 0.184 & 0.113 & 1.340 & 0.934 & 1.923 \\
HAQ & 0.267 & 0.088 & 0.002 & 1.306 & 1.100 & 1.552 \\
Constant & 1.225 & 0.180 & 0.000 & 3.404 & 4.393 & \\
\hline
\end{tabular}

Anti-CCP positivity $=>25 \mathrm{IU} / \mathrm{ml}$. Italicized values are significant. Unacceptable pain defined as VAS pain $>40 \mathrm{~mm}$

DAS28 28 joints-Disease Activity Score, HAQ Health Assessment Questionnaire

the femoral neck/Ward's triangle measured by DEXA than those who were anti-CCP negative. Further, anti-CCP positivity was independently associated with osteopenia in these hip locations. This observation corresponds to a recent report that has suggested a possible direct role of ACPA on bone metabolism. However, anti-CCP was not associated with high pain perception in this study.

The frequency of osteopenia was of the same magnitude as previously reported in early RA [20] and was, at diagnosis, not associated with disease-related variables, such as disease activity or functional impairment, variables known to be associated with systemic bone loss in established RA [1]. However, RA-related autoimmunity may induce bone loss in absence of overt inflammation. Thus, altered bone metabolism has been shown already in the preclinical phase of anti-CCP-positive individuals [31].

In the present study, the presence of anti-CCP was not associated with osteopenia in the lumbar spine, which might depend on the fact that BMD measurement of the lumbar spine by DEXA is influenced by its sensitivity to degenerative and osteoarthritic changes, which can result in incorrect values. Another possibility is that anti-CCP autoantibodies early in the disease do not yet contribute to systemic osteopenia in bone remote from the inflamed joints. Contrary to our results, in a cohort with early RA from Italy, an association between anti-CCP positivity and lumbar spine osteopenia has been reported [21]. However, there are significant differences between the cohorts. Thus, in Bugatti's cohort, fewer patients were anti-CCP and RF positive, 43 and $43 \%$, respectively, compared with 58 and $60 \%$ in the present patients, and only $26 \%$ had osteopenia in the lumbar spine compared with the present $37 \%$. Furthermore, only $69 \%$ in Bugatti's cohort satisfied the ACR 1987 criteria for RA. These cohort differences make comparisons of the results problematic.

Also, in a Spanish cohort of early arthritis (a PEARL study) with $38 \%$ anti-CCP-positive patients, an association between anti-CCP positivity and low bone density in lumbar spine was demonstrated [32]. This cohort included both patients fulfilling the ACR/EULAR 2010 RA criteria (55\%) and patients with undifferentiated arthritis, spondyloarthropathies, osteoarthritis, connective tissue disorders, and miscellaneous conditions. Besides the heterogenous population, the fact that a good $20 \%$ of the patients were on glucocorticoid therapy makes the PEARL and BARFOT cohorts difficult to compare. In a randomized study of early addition of prednisolone $7.5 \mathrm{mg} /$ day to the first DMARD in patients diagnosed with RA, we have shown that the effect of glucocorticoids on the bone can be both beneficial (hip) and deleterious (lumbar spine) [33].

The differences in associations between anti-CCP and BMD in the different hip compartments may depend on the fact that their bone mineral density declines differently with age. Thus, in elderly individuals, BMD in Ward's triangle is lower than that in the other hip compartments [34] and may be more influenced by anti-CCP-related autoimmunity. This is in line with the finding of bone loss in the cortical bone of the total hip only by high anti-CCP titers in the Bugatti cohort [21]. However, anti-CCP positivity was associated with osteopenia in both total hip and femoral neck in the PEARL study [32].

In men, anti-CCP at any titer was associated with osteopenia in the hip, while in women this association was found only at higher titers of anti-CCP. It is well-known that ACPAs develop several years ahead of the diagnosis of RA and that the number of citrullinated peptides increases over time in a random manner as well as the antibody titer [11]. However, none of the studies describing this phenomenon has separated the results per gender [8-13]. Furthermore, gender was not considered in analyses of the titer-dependent role of ACPA on bone loss in the hip in established RA [35, 36].

In the present study, women and men had the same frequency of anti-CCP positivity as well as the same frequency of anti-CCP titer above $500 \mathrm{IU} / \mathrm{ml}$. However, we have no information of whether epitope spreading and the number of ACPA isotypes differed. Besides, the identity of the molecule(s) on osteoclasts targeted by ACPA 
remains unresolved [5]. Therefore, it is so far not known if different antigens are targeted in a different manner in women and men with RA. The finding of more likely osteopenia in Ward in women older than 50 years compared with women younger than 50 years in our study suggests the importance of studying postmenopausal systemic bone remodeling in addition to autoantibody-dependent bone changes.

The association between anti-CCP positivity and osteopenia in the femoral neck/Ward in the present study does not allow any inferences of causality but fits well with recent reports linking ACPA to autoantibody-mediated bone loss $[15,16]$. However, also other autoantibodies may contribute to bone loss in patients with RA. Thus, the association between anti-CCP positivity and BMD loss was reported to be enhanced in the presence of concomitant high levels of RF autoantibodies [21]. In our study, RF per se was not associated with osteopenia; however, because of variation in the used assays, dose-dependent RF effect was not examined.

Interestingly, anti-carbamylated protein (anti-CarP) autoantibodies, additive to ACPA and RF, have been associated with more severe radiographic progression in patients with early RA [37]. Thus, several autoantibodies might have pathogenic effect on osteoclasts. Recently, it has been reported that in the anti-CCP-positive patients with early arthritis, high titers of anti-CarP have contributed to finding of osteopenia in both lumbar spine and hip [38].

Neither presence of anti-CCP nor high titers of anti-CCP were associated with metacarpal (MCP) cortical bone osteopenia assessed by DXR. This might be explained by the lower turnover rate in the cortical bone compared to the trabecular bone. A study performed with micro computed tomography has shown thinning and fenestration of the cortical bone in the MCP in anti-CCP-positive healthy individuals [18]. In the studies of RA, loss of the metacarpal cortical bone, assessed by DXR, occurs early upon the diagnosis of both undifferentiated arthritis and RA $[29,39]$. In these studies of early RA, the effect of ACPA on bone loss was not evaluated. On the other hand, in established disease with a disease duration of 2 to 4 years, elevated anti-CCP levels independently predicted loss of the cortical hand bone during a study period of 5 years [40].

Anti-CCP positivity was not associated with unacceptable pain in this study. Instead, inflammation seemed to play an important role in pain experience before treatment initiation. In RA, pain is mostly attributed to inflammation, but non-inflammatory pain exists and may confound disease activity assessments by, e.g., DAS28 [41].

In the present study, the patient reported pain was assessed by VAS, which does not specify the kind or character of pain. The pain is suggested to be of peripheral nociceptive origin, possibly with peripheral sensitization as peripheral sensitization due to inflammation can amplify pain [42]. The lack of an association of anti-CCP with unacceptable pain may depend on different effects of ACPA on inflammatory-dependent and non-inflammatory pain.

Induction of pain by ACPA has been reported in mice [17], and it has further been suggested that the arthralgia preceding RA in ACPA-positive individuals may be a direct consequence of osteoclast activation linked to certain ACPAs via an IL-8-dependant pathway [5].

The role of ACPA in the pathogeneses of RA remains unclear. In many patients, treatment with disease-modifying agents reduces inflammation and pain, whereas the level of anti-CCP remains stable over time [43]. However, the ACPA response differs markedly across specificities, which suggests that only some ACPAs are pathogenic [43].

There are limitations in this study. First, this is an observational study not designed to study causal relationships. Furthermore, the possibility of subgroup analyses was limited by the relatively small number of patients available. It should also be noted that DEXA measures only bone mass and not bone microstructure nor biomechanical properties of bone. Although information on hormone replacement therapy was lacking, it should not influence our findings on the association between anti-CCP positivity and osteopenia as the postmenopausal women were similarly represented among anti-CCP-positive and anti-CCP-negative RA patients.

To recall, the present analysis of the second-generation anti-cyclic citrullinated peptide (anti-CCP2) does not detect all anti-citrullinated protein/peptide antibodies (ACPAs) [44]. Thus, a subgroup of anti-CCP-negative patients in our study may still display ACPA reactivity. Furthermore, the lack of statistically proven association of anti-CCP positivity with unacceptable pain should be interpreted with caution as a negative finding may depend not only on sample size, definition of pain, and different effects of ACPA on inflammatory-dependent and non-inflammatory pain, but also on co-existence of other autoantibody systems, not measured here, possibly affecting pain. However, considering pain burden important for the patients, the outcome of unacceptable pain in this study appears to be relevant.

\section{Conclusion}

Our data show that in patients with early RA, anti-CCP positivity, independently of inflammation, is associated with osteopenia in the femoral neck and Ward, but not with unacceptable pain. Further studies are necessary to explore the possible clinical relevance of interactions between ACPA, bone remodeling, and pain reported in vitro and in animal models. 


\section{Abbreviations}

ACPA: Anti-citrullinated protein antibodies; Anti-CarP: Anti-carbamylated protein; Anti-CCP: Anti-cyclic citrullinated antibodies; BARFOT: Better AntiRheumatic PharmacOTherapy; BMD: Bone mineral density; BMI: Body mass index; CRP: C-reactive protein; DAS28: Disease Activity Score calculated on 28 joints; DEXA: Dual-energy X-ray absorptiometry; DMARD: Disease-modifying anti-rheumatic drug; DXR: Digital X-ray radiogrammetry; ESR: Erythrocyte sedimentation rate; HAQ: Health Assessment Questionnaire; IL: Interleukin; L: Lumbar spine; MCP: Metacarpophalangeal joint; PEARL: Princesa Early Arthritis Register Longitudinal; RA: Rheumatoid arthritis; RF: Rheumatoid factor; VAS: Visual analogue scale

\section{Acknowledgements}

We thank all the members of the BARFOT study group.

\section{Funding}

The study was funded by grants from The Swedish Rheumatism Association and the Foundation for Assistance to Disabled People in Skåne.

\section{Availability of data and materials}

The data analyzed during the current study are available from the corresponding author on reasonable request.

\section{Authors' contributions}

$\mathrm{IH}$ and $\mathrm{BS}$ designed the study. $\mathrm{H}, \mathrm{SA}$, and KF were responsible for acquisition of the data, which were analyzed by BS. All authors contributed to interpretation of the data and were involved in drafting the manuscript or revising it critically. All authors approved the final version of the manuscript to be published.

\section{Ethics approval and consent to participate}

All patients gave their informed consent to the study, which was performed in accordance with the Helsinki Declaration. The following ethics committees approved the study: Lund university LU 154-95 and 398-01; Göteborg university Gbg M 45-95 and Ö 282-01; Linköping university Li 123-95 and 01-263; Karolinska Institutet KI 153-95 and 02-075.

\section{Consent for publication}

Not applicable.

\section{Competing interests}

The authors declare that they have no competing interests.

\section{Publisher's Note}

Springer Nature remains neutral with regard to jurisdictional claims in published maps and institutional affiliations.

\section{Author details \\ ${ }^{1}$ Division of Gastroenterology and Rheumatology, Department of Medicine, Huddinge, Karolinska Institutet, and Rheumatology unit R92, Karolinska University Hospital, Stockholm, SE 141 86, Sweden. ²Division of Gastroenterology and Rheumatology, Department of Medicine, Karolinska Institutet, Huddinge, Sweden. ${ }^{3}$ Rheumatology Division, Universitair Ziekenhuis Brussel, Vrije Universiteit Brussel, Brussels, Belgium. ${ }^{4}$ Department of Clinical Science, Section of Rheumatology, Faculty of Medicine, Lund University, Lund, Sweden. ${ }^{5}$ Department of Research Education, Skånevård Sund, Region Skåne, Helsingborg's hospital, Helsingborg, Sweden. ${ }^{6}$ Department of Clinical Science, Section of Rheumatology, Faculty of Medicine Lund University, Lund, Sweden.}

\section{Received: 18 October 2018 Accepted: 21 January 2019}

\section{Published online: 04 February 2019}

\section{References}

1. Haugeberg G, Uhlig T, Falch JA, Halse JI, Kvien TK. Bone mineral density and frequency of osteoporosis in female patients with rheumatoid arthritis: results from 394 patients in the Oslo County Rheumatoid Arthritis register. Arthritis Rheum. 2000:43(3):522-30.

2. Taylor P, Manger B, Alvaro-Gracia J, Johnstone R, Gomez-Reino J, Eberhardt

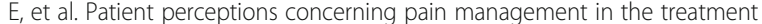
of rheumatoid arthritis. J Int Med Res. 2010;38(4):1213-24.
3. Lee YC, Nassikas NJ, Clauw DJ. The role of the central nervous system in the generation and maintenance of chronic pain in rheumatoid arthritis, osteoarthritis and fibromyalgia. Arthritis Res Ther. 2011;13(2):211.

4. Andersson ML, Svensson B, Bergman S. Chronic widespread pain in patients with rheumatoid arthritis and the relation between pain and disease activity measures over the first 5 years. J Rheumatol. 2013;40(12):1977-85.

5. Catrina Al, Svensson Cl, Malmstrom V, Schett G, Klareskog L. Mechanisms leading from systemic autoimmunity to joint-specific disease in rheumatoid arthritis. Nat Rev Rheumatol. 2017;13(2):79-86.

6. van Zanten A, Arends S, Roozendaal C, Limburg PC, Maas F, Trouw LA, et al. Presence of anticitrullinated protein antibodies in a large population-based cohort from the Netherlands. Ann Rheum Dis. 2017;76(7):1184-90.

7. Nam JL, Hunt L, Hensor EM, Emery P. Enriching case selection for imminent RA: the use of anti-CCP antibodies in individuals with new non-specific musculoskeletal symptoms - a cohort study. Ann Rheum Dis. 2016;75(8):1452-6.

8. Rantapaa-Dahlqvist S, de Jong BA, Berglin E, Hallmans G, Wadell G, Stenlund $\mathrm{H}$, et al. Antibodies against cyclic citrullinated peptide and IgA rheumatoid factor predict the development of rheumatoid arthritis. Arthritis Rheum. 2003:48(10):2741-9.

9. Nielen MM, van Schaardenburg D, Reesink HW, van de Stadt RJ, van der Horst-Bruinsma IE, de Koning $\mathrm{MH}$, et al. Specific autoantibodies precede the symptoms of rheumatoid arthritis: a study of serial measurements in blood donors. Arthritis Rheum. 2004:50(2):380-6.

10. van der Woude D, Rantapaa-Dahlqvist S, loan-Facsinay A, Onnekink C, Schwarte CM, Verpoort KN, et al. Epitope spreading of the anti-citrullinated protein antibody response occurs before disease onset and is associated with the disease course of early arthritis. Ann Rheum Dis. 2010;69(8):1554-61.

11. van de Stadt LA, de Koning MH, van de Stadt RJ, Wolbink G, Dijkmans BA, Hamann D, et al. Development of the anti-citrullinated protein antibody repertoire prior to the onset of rheumatoid arthritis. Arthritis Rheum. 2011 63(11):3226-33.

12. Brink M, Hansson M, Mathsson L, Jakobsson PJ, Holmdahl R, Hallmans $G$ et al. Multiplex analyses of antibodies against citrullinated peptides in individuals prior to development of rheumatoid arthritis. Arthritis Rheum. 2013;65(4):899-910.

13. Kokkonen H, Mullazehi M, Berglin E, Hallmans G, Wadell G, Ronnelid J, et al. Antibodies of $\lg G, \lg A$ and $\lg M$ isotypes against cyclic citrullinated peptide precede the development of rheumatoid arthritis. Arthritis Res Ther. 2011;13(1):R13.

14. Sokolove J, Bromberg R, Deane KD, Lahey $\sqcup$, Derber LA, Chandra PE, et al. Autoantibody epitope spreading in the pre-clinical phase predicts progression to rheumatoid arthritis. PLoS One. 2012;7(5):e35296.

15. Harre U, Georgess D, Bang H, Bozec A, Axmann R, Ossipova E, et al. Induction of osteoclastogenesis and bone loss by human autoantibodies against citrullinated vimentin. J Clin Invest. 2012;122(5):1791-802.

16. Krishnamurthy A, Joshua V, Haj Hensvold A, Jin T, Sun M, Vivar N, et al. Identification of a novel chemokine-dependent molecular mechanism underlying rheumatoid arthritis-associated autoantibody-mediated bone loss. Ann Rheum Dis. 2016;75(4):721-9.

17. Wigerblad G, Bas DB, Fernades-Cerqueira C, Krishnamurthy A, Nandakumar KS, Rogoz K, et al. Autoantibodies to citrullinated proteins induce joint pain independent of inflammation via a chemokine-dependent mechanism. Ann Rheum Dis. 2016;75(4):730-8.

18. Kleyer A, Finzel S, Rech J, Manger B, Krieter M, Faustini F, et al. Bone loss before the clinical onset of rheumatoid arthritis in subjects with anticitrullinated protein antibodies. Ann Rheum Dis. 2014;73(5):854-60.

19. Keller KK, Thomsen JS, Stengaard-Pedersen K, Nielsen AW, SchiottzChristensen B, Svendsen L, et al. Local bone loss in patients with anticitrullinated peptide antibody and arthralgia, evaluated with high-resolution peripheral quantitative computed tomography. Scand J Rheumatol. 2018; 47(2):110-6.

20. Keller C, Hafstrom I, Svensson B. Bone mineral density in women and men with early rheumatoid arthritis. Scand J Rheumatol. 2001;30(4):213-20.

21. Bugatti S, Bogliolo L, Vitolo B, Manzo A, Montecucco C, Caporali R. Anticitrullinated protein antibodies and high levels of rheumatoid factor are associated with systemic bone loss in patients with early untreated rheumatoid arthritis. Arthritis Res Ther. 2016;18(1):226.

22. Arnett FC, Edworthy SM, Bloch DA, McShane DJ, Fries JF, Cooper NS, et al. The American Rheumatism Association 1987 revised criteria for the classification of rheumatoid arthritis. Arthritis Rheum. 1988;31(3):315-24.

23. Svensson B, Schaufelberger C, Teleman A, Theander J. Remission and response to early treatment of RA assessed by the Disease Activity Score. 
BARFOT study group. Better Anti-rheumatic Farmacotherapy. Rheumatology (Oxford). 2000;39(9):1031-6.

24. Prevoo ML, van 't Hof MA, Kuper $H H$, van Leeuwen $M A$, van de Putte $L B$, van Riel PL. Modified disease activity scores that include twenty-eight-joint counts. Development and validation in a prospective longitudinal study of patients with rheumatoid arthritis. Arthritis Rheum. 1995;38(1):44-8.

25. van Gestel AM, Haagsma CJ, van Riel PL. Validation of rheumatoid arthritis improvement criteria that include simplified joint counts. Arthritis Rheum. 1998;41(10):1845-50

26. Tubach F, Ravaud P, Martin-Mola E, Awada H, Bellamy N, Bombardier C, et al. Minimum clinically important improvement and patient acceptable symptom state in pain and function in rheumatoid arthritis, ankylosing spondylitis, chronic back pain, hand osteoarthritis, and hip and knee osteoarthritis: results from a prospective multinational study. Arthritis Care Res (Hoboken). 2012;64(11):1699-707.

27. Ekdahl C, Eberhardt K, Andersson SI, Svensson B. Assessing disability in patients with rheumatoid arthritis. Use of a Swedish version of the Stanford Health Assessment Questionnaire. Scand J Rheumatol. 1988;17(4):263-71.

28. Rosholm A, Hyldstrup L, Backsgaard L, Grunkin M, Thodberg HH. Estimation of bone mineral density by digital X-ray radiogrammetry: theoretical background and clinical testing. Osteoporos Int. 2001;12(11):961-9.

29. Forslind K, Kalvesten J, Hafstrom I, Svensson B. Does digital X-ray radiogrammetry have a role in identifying patients at increased risk for joint destruction in early rheumatoid arthritis? Arthritis Res Ther. 2012;14(5):R219.

30. Black DM, Palermo L, Sorensen T, Jorgensen JT, Lewis C, Tylavsky F, et al. A normative reference database study for Pronosco X-posure System. J Clin Densitom. 2001:4(1):5-12.

31. van Schaardenburg D, Nielen MM, Lems WF, Twisk JW, Reesink HW, van de Stadt RJ, et al. Bone metabolism is altered in preclinical rheumatoid arthritis. Ann Rheum Dis. 2011;70(6):1173-4.

32. Llorente I, Merino L, Ortiz AM, Escolano E, Gonzalez-Ortega S, Garcia-Vicuna $\mathrm{R}$, et al. Anti-citrullinated protein antibodies are associated with decreased bone mineral density: baseline data from a register of early arthritis patients. Rheumatol Int. 2017;37(5):799-806.

33. Engvall IL, Svensson B, Tengstrand B, Brismar K, Hafstrom I. Impact of lowdose prednisolone on bone synthesis and resorption in early rheumatoid arthritis: experiences from a two-year randomized study. Arthritis Res Ther. 2008;10(6):R128

34. Karlsson MK, Gardsell P, Johnell O, Nilsson BE, Akesson K, Obrant KJ. Bone mineral normative data in Malmo, Sweden. Comparison with reference data and hip fracture incidence in other ethnic groups. Acta Orthop Scand. 1993; 64(2):168-72.

35. Orsolini G, Caimmi C, Viapiana O, Idolazzi L, Fracassi E, Gatti D, et al. Titerdependent effect of anti-citrullinated protein antibodies on systemic bone mass in rheumatoid arthritis patients. Calcif Tissue Int. 2017;101(1):17-23.

36. Wysham KD, Shoback DM, Imboden JB Jr, Katz PP. Association of high anticyclic citrullinated peptide seropositivity and lean mass index with low bone mineral density in rheumatoid arthritis. Arthritis Care Res (Hoboken). 2018;70(7):961-9.

37. Ajeganova S, van Steenbergen HW, Verheul MK, Forslind K, Hafstrom I, Toes $\mathrm{RE}$, et al. The association between anti-carbamylated protein (anti-CarP) antibodies and radiographic progression in early rheumatoid arthritis: a study exploring replication and the added value to ACPA and rheumatoid factor. Ann Rheum Dis. 2017;76(1):112-8.

38. Regueiro C, Ortiz AM, Boveda MD, Castaneda S, Gonzalez-Alvaro I, Gonzalez A. Association of high titers of anti-carbamylated protein antibodies with decreased bone mineral density in early arthritis patients. PLoS One. 2018; 13(8):e0202583.

39. de Rooy DP, Kalvesten J, Huizinga TW, van der Helm-van Mil AH. Loss of metacarpal bone density predicts RA development in recent-onset arthritis. Rheumatology. 2012;51(6):1037-41.

40. Boyesen P, Hoff M, Odegard S, Haugeberg G, Syversen SW, Gaarder PI, et al. Antibodies to cyclic citrullinated protein and erythrocyte sedimentation rate predict hand bone loss in patients with rheumatoid arthritis of short duration: a longitudinal study. Arthritis Res Ther. 2009;11(4):R103.

41. McWilliams DF, Kiely PDW, Young A, Joharatnam N, Wilson D, Walsh DA Interpretation of DAS28 and its components in the assessment of inflammatory and non-inflammatory aspects of rheumatoid arthritis. BMC Rheumatology. 2018;2:8.

42. Schaible HG, Richter F, Ebersberger A, Boettger MK, Vanegas H, Natura G, et al. Joint pain. Exp Brain Res. 2009;196(1):153-62.
43. Kastbom A, Forslind K, Ernestam S, Geborek P, Karlsson JA, Petersson IF. Changes in the anticitrullinated peptide antibody response in relation to therapeutic outcome in early rheumatoid arthritis: results from the SWEFOT trial. Ann Rheum Dis. 2016;75(2):356-61.

44. Ronnelid J, Hansson M, Mathsson-Alm L, Cornillet M, Reed E, Jakobsson PJ, et al. Anticitrullinated protein/peptide antibody multiplexing defines an extended group of ACPA-positive rheumatoid arthritis patients with distinct genetic and environmental determinants. Ann Rheum Dis. 2018;77(2):203-11.

\section{Ready to submit your research? Choose BMC and benefit from:}

- fast, convenient online submission

- thorough peer review by experienced researchers in your field

- rapid publication on acceptance

- support for research data, including large and complex data types

- gold Open Access which fosters wider collaboration and increased citations

- maximum visibility for your research: over $100 \mathrm{M}$ website views per year

At BMC, research is always in progress.

Learn more biomedcentral.com/submissions 